\title{
Property level flood protection: a new effective and affordable solution
}

\author{
D. W. Beddoes ${ }^{1,2} \&$ C. A. Booth ${ }^{1}$ \\ ${ }^{I}$ School of Engineering and the Built Environment, \\ University of Wolverhampton, $U K$ \\ ${ }^{2}$ Mickley Cottages, Tern Hill, UK
}

\begin{abstract}
Property flooding is a major problem and the risk of flooding continues to escalate. At present, the majority of property owners take no steps to mitigate future flood damage. A review of the main factors influencing the uptake of flood protection reveals property owners have the desire to act but not the ability to act. The latter involves making choices, which require knowledge, belief and finance. Unfortunately, there seems to be no choice of measures both acceptable to the property owner and also offer full property protection, which may be the main reason for a lack of uptake. A new innovative solution, known as 'The Flexible Skirting System' (patent GB2452423), is presented, which is a cost effective combination of resistance and resilience approaches. Compared to other flood protection measures already commercially available, the system is quick and simple to install, aesthetically acceptable, offers less disruption and is affordable. Moreover, this system is possibly the choice needed to enable property owners to make the decision to install flood protection against all routes of floodwater ingress.
\end{abstract}

Keywords: flood, property, resistance, resilience, cost, solution, government grant.

\section{Introduction}

The number of global disasters attributable to floods is increasing [1]. Concomitantly, society is beginning to experience changes in wind patterns, storm intensity, storm frequency, and rainfall [2]. Climate change, coupled with increased societal pressure to further develop on floodplains, will result in a 
greater overload of infrastructure [3]. In turn, this promises an ever increasing risk of flood events for property owners $[4,5]$.

To address issues surrounding flood resistance and resilience measures acceptable to property owners, this paper outlines the context for necessary changes to existing approaches and introduces a new innovative solution to property level flood protection.

\section{The lack of uptake of flood protection}

The majority of property owners who live in high risk flood areas have not yet adopted any flood protection despite the high profile attention given to flood events by the media [6]. Consequently, the installation of property level protection remains low. For instance, a leading insurance company, Norwich Union, recently surveyed 1500 UK flood victims and found $83 \%$ still believe there is nothing they can do to mitigate future flooding [7]. This is further supported by a survey conducted for the Department for Environment Food and Rural Affairs (DEFRA), which found in areas of significant flood risk only 16\% of households had taken any practical steps to limit potential flood damage [8]. Even those with properties flooded several times before have taken only minimal action, often installing measures that are ineffective [8]. Those property owners who have taken action have, very often, been advised by retailers of flood products promoting their own external aperture guards. However, these guards may become ineffective when applied as a sole means of protection.

\section{Making the decision at property level}

To make decision pertaining to the installation of flood protection measures, the property owner must go through several stages grouped into two major phases: the 'desire to act' and the 'ability to act' [9]. Each of the three stages must be satisfied to complete a phase and the property owner will only act when both phases are completed. These two phases are now examined further.

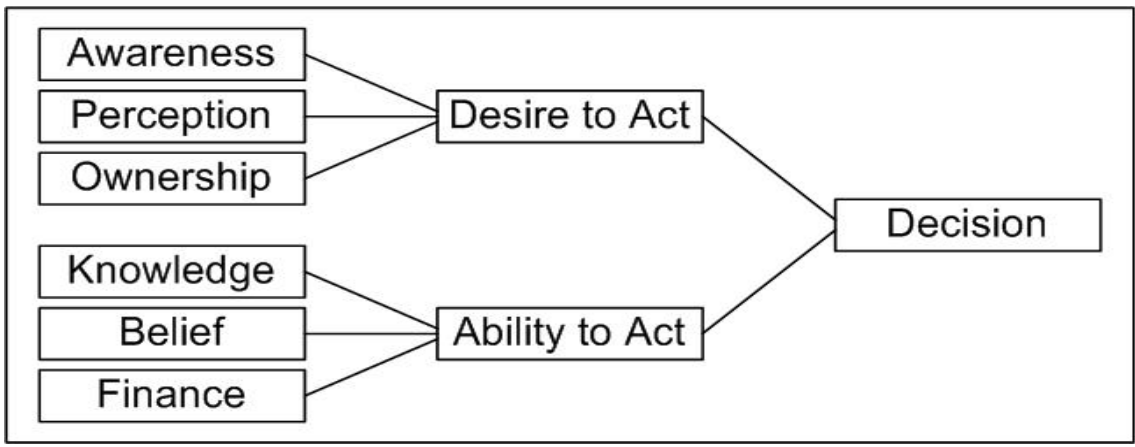

Figure 1: The stages and subsequent phases to be satisfied to enable a decision (after [9]). 


\subsection{Phase I - The desire to act - awareness, perception, and ownership}

The UK government has made a continuous effort to raise flood awareness by using the Environment Agency (EA) to run extensive, successful media campaigns. Flood maps are publicly available on the EA website. Entering the postcode of a property will give a flooding probability and these are now used as part of local search data for property purchases. Harries [6] maintains that $60 \%$ of 'at risk property owners' in a survey done in 2004 were aware they lived in an 'at risk area' and this was before the publicity afforded to major floods of summer 2007. A recent DEFRA [8] survey of 1,131 individuals at significant risk of flooding found the majority to be aware of the fact they were in flood risk areas. Perception or understanding requires the property owner to face the unpleasant possibility of floodwater entering their property. Recurrent UK flood events and their extensive media coverage increased the receptiveness of a population to messages about flood risk [10]. Perception has been greatly helped by stating chance as 1 in 75 as opposed to a $1.3 \%$ probability; the general public do not always understand percentages. Government information has strongly emphasised to the public that a flooded home is the responsibility of the property owner and this seems to be widely acknowledged and accepted. Similarly, the UK government have realised that central government funded large-scale resistance at community level is no longer sustainable [11]. That said, this new strategy is not confined to the UK [12]. A survey by Werritty et al. [13] showed property owners have now accepted some responsibility. Ownership of the problem is also being revealed to the property owner because of the ever increasing difficulty of finding flood-cover as part of a buildings insurance policy and, in some cases, insurance cover is not now always available. Therefore, property owners appear to have the awareness, perception and ownership to satisfy Phase I - the desire to act.

\subsection{Phase II - The ability to act - knowledge, belief, and finance}

Sandbags, although regarded by experts as useless, are still the public perception of flood protection [14]. A recent DEFRA [8] survey asked property owners about flood products, with over half of the respondents outlining they were not confident in their ability to choose the right measures to protect their properties [8]. Doubt over how to act can be an important barrier to flood risk response [6]. Broadbent [15] concluded much can be done by the property owner but each property is different and the property owner needs specialist advice. There is little belief or confidence in flood protection measures due to the experience of poorly performing or inappropriately chosen defence strategies [9]. Examples of expensive resistance products, likely ineffective when deployed in isolation, are widespread. This situation, coupled with the availability of a bewildering array of flood products, peddled in some cases by 'double glazing salesmen', leads to a lack of confidence in all flood products [16]. Financing flood protection will always be a problem for property owners when knowledge and confidence in products is inadequate. Especially when most households presume protection is 
too expensive [8]. In all likelihood, it appears, when the property owner reaches the stages of knowledge, belief and finance they are not able to progress further and cannot complete Phase II - the ability to act.

\section{Current flood protection measures}

There remains a very low take-up of property level flood protection. A small proportion of property owners develop a coping strategy of avoiding anxiety by denial of risk, but the majority want to act to protect their property [6]. Therefore, a property owner's inability to choose from a vast array of available measures and products is problematic. Particularly as property owners have no expertise in this area and, moreover, the flood protection design is a complex process [15]. The choice for existing properties is between resistance and resilience. External resistance measures are mostly acceptable to property owners but they do not always offer full protection; whereas, resilience measures offer internal protection but disruption, and daily reminder, can seriously affect lives [17]. Normality of home life is needed by flood victims [18]. Therefore, a new system is needed that can be installed with minimum disruption to provide protection against all routes of water ingress; whilst, also being aesthetically acceptable. Furthermore, the system must be simple and straight-forward so the property owner can easily understand its operation and, moreover, it must be affordable.

\section{A system to address all routes of water ingress}

The Flexible Skirting System (patent GB2452423) may be the product needed to enable property owners to make the decision to install property level flood protection, as recommended in the Pitt Review [19]. For a property with solid ground floors the normal routes of water ingress are doors, floors at the bottom of walls and toilets $[15,20]$. These routes are in agreement with the survey carried-out by CIRIA on the owners of flooded properties that gave the following water ingress paths; $88 \%$ through openings, $46 \%$ seeping through walls and floors and 37\% through drains [21]. With this system external resistance measures (e.g. door guards) are combined with a hollow skirting that collects flood water at the vulnerable wall/floor join. When used with a drain backflow valve this provides complete protection against water ingress. The front face of The Flexible Skirting System is sealed to the top of a floor membrane. Water enters at the base of the wall where hydrostatic pressure is the greatest, the rate of ingress through a masonry wall being quite low, and a $350 \mathrm{~W}$ pump having the capacity to remove water entering at the maximum rate of ingress via a sump/pump [22]. Figure 2 displays a cross section of the system, the arrows show water ingress routes. Holes drilled through the inner leaf of a cavity wall will keep the cavity free from water ingress. 


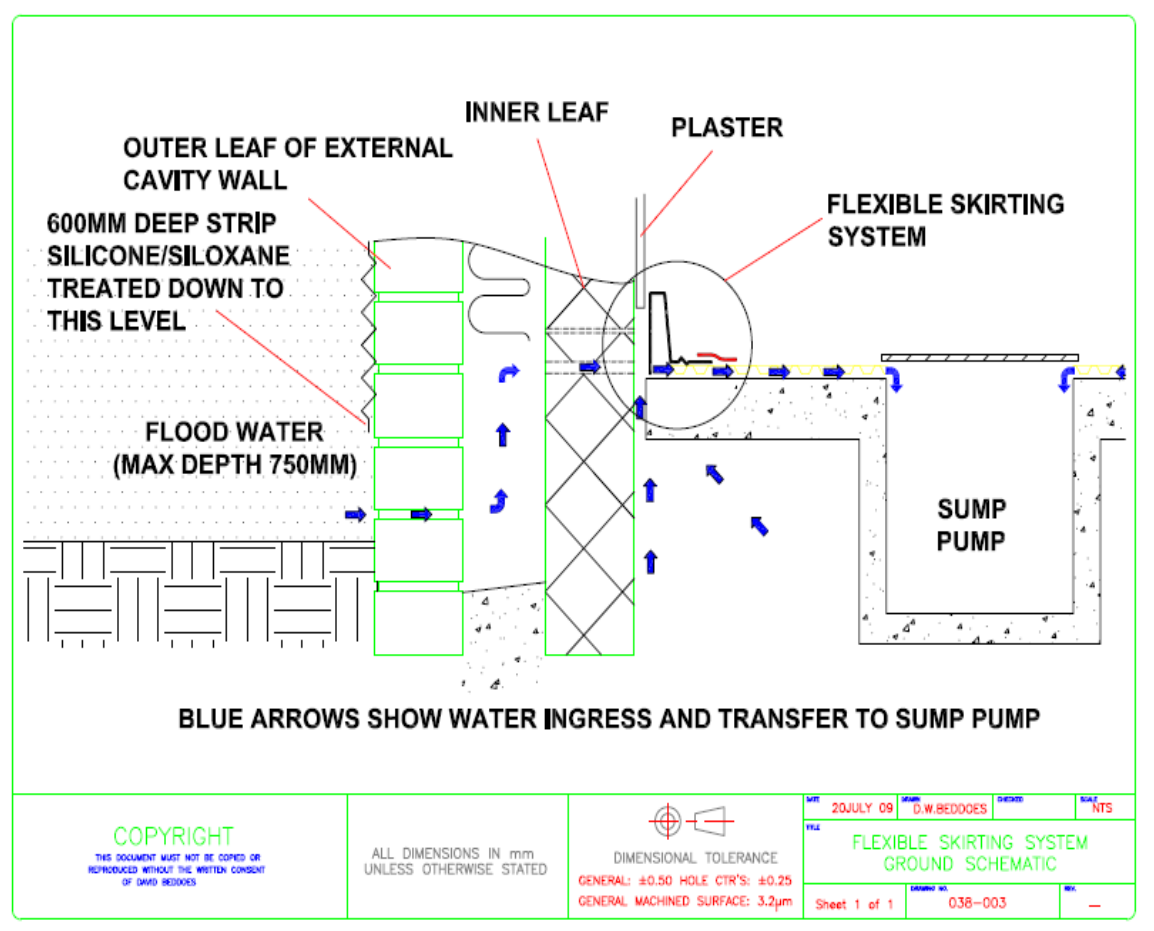

Figure 2: $\quad$ A cross section drawing of The Flexible Skirting System.

\section{Comparison to current solutions}

Resistance measures, typically costing $\sim £ 3,000$ for an average property, are acceptable to property owners but can be ineffective due to groundwater and party wall water ingress. Resilient construction (internal tiled walls etc.) where property owner must let water into the home, typically costing $\sim £ 24,000$ for an average property, is not always acceptable to the property owner, as it puts the security of the property under threat [18]. Full internal tanking is too expensive and too disruptive for the property owner, typically costing $\sim £ 30,000$.

The Flexible Skirting System, costing $\sim £ 7,000$ for an average property, provides full property protection and can be installed at any time. The system is easy and simple to install with minimum disruption (Figures 3 and 4). It is aesthetically acceptable and can be sanitised and dried-out after each flood event. Any damage to plasterwork can be addressed after the flood event via insurance, but the importance of keeping the property owner in their home by using this system cannot be overemphasised [17, 23-26]. 
276 Flood Recovery, Innovation and Response II

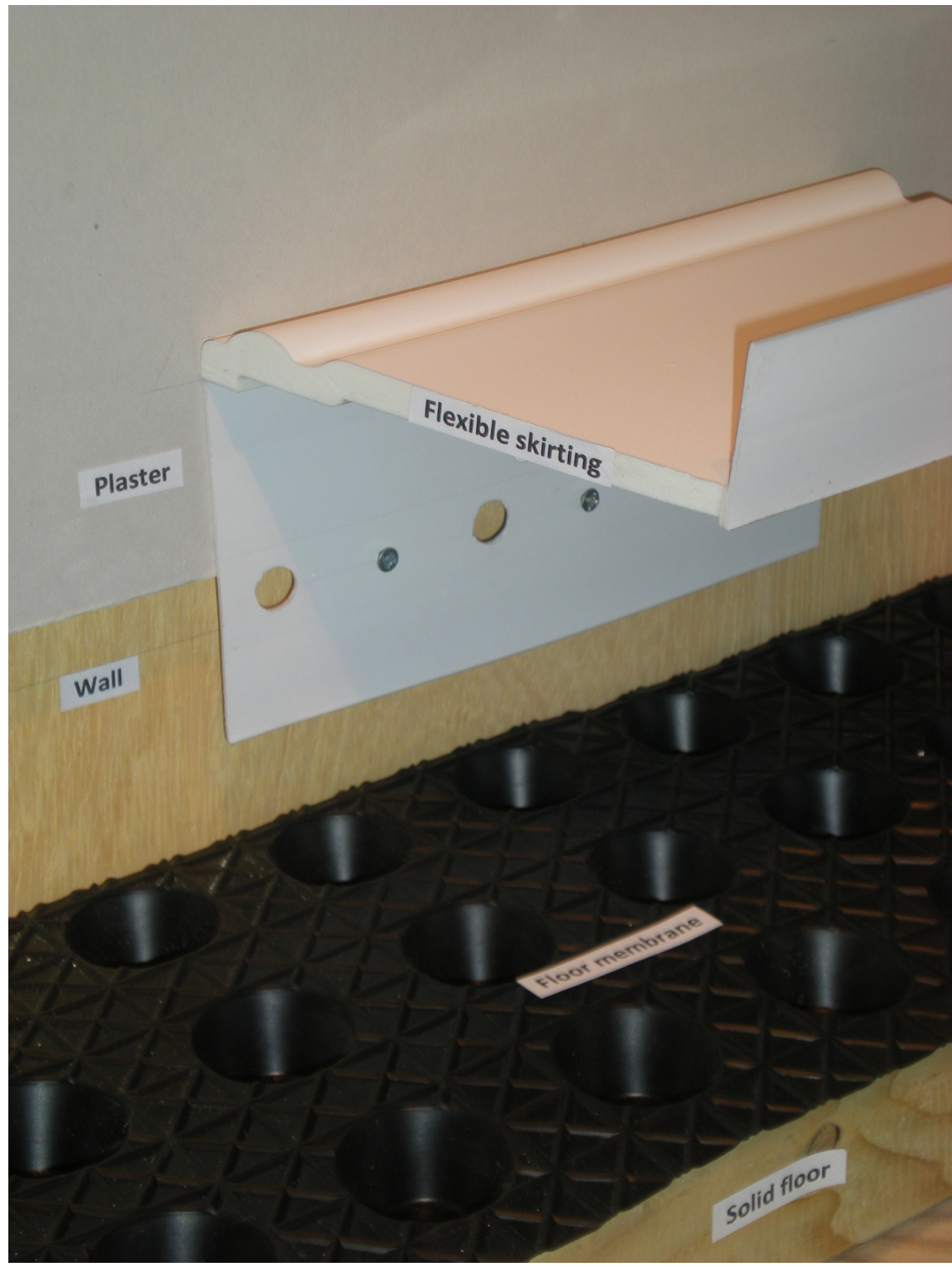

Figure 3: The Flexible Skirting System with the rear face fixed to wall and the front face lifted for viewing. 


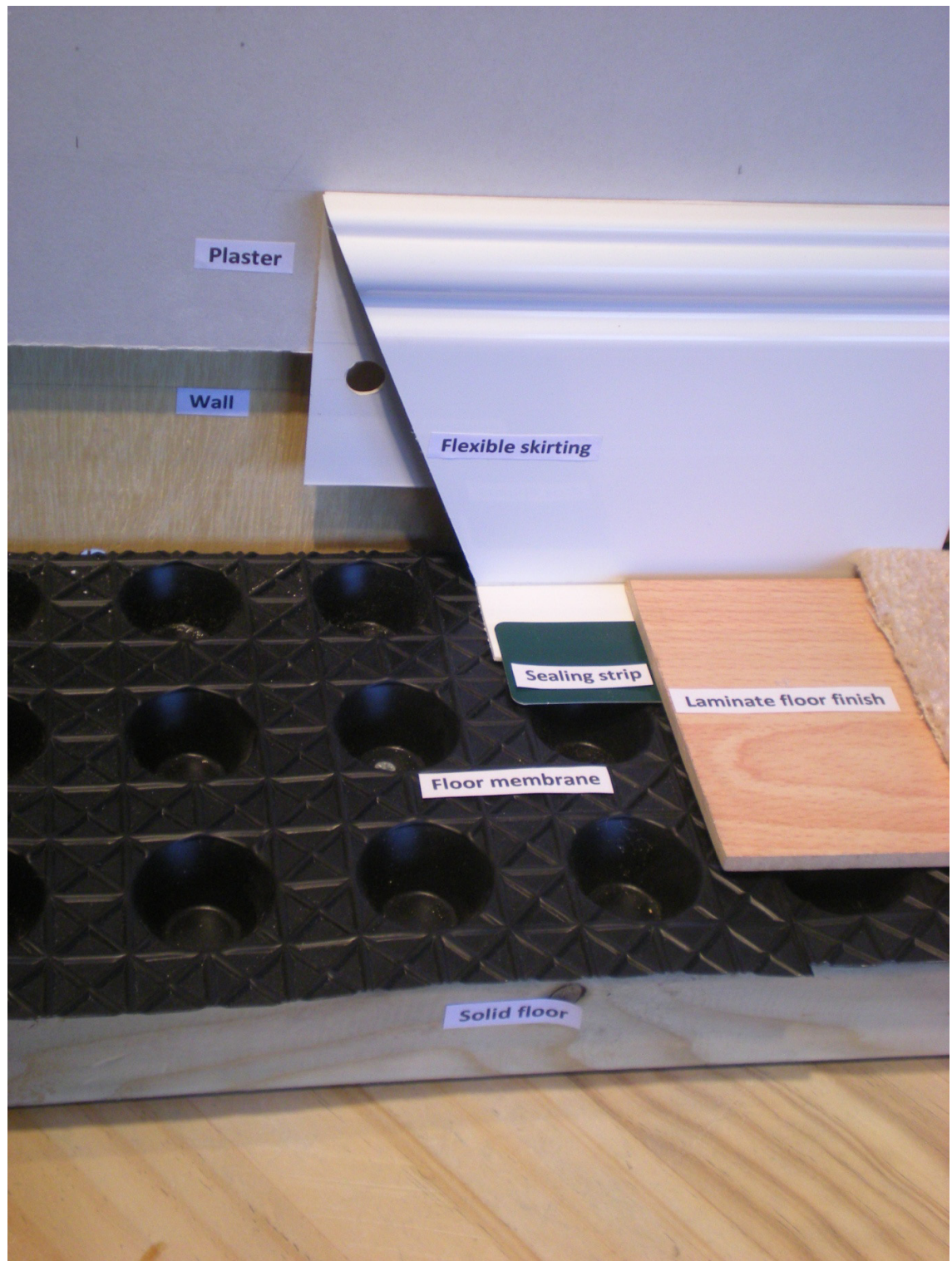

Figure 4: Installation of ogee section with sealed join to floor membrane and laminate floor finish.

\section{Discussion}

It is important to remember the human misery and suffering caused by flood events. Floods are the most destructive natural disaster to affect humans [25]. In 
general, Fundter [18] found residents have a natural resistance to evacuation, regardless of the severity of the threat, and a consequence of evacuation causes lasting mental health problems. In order to make the decision to install flood protection, the property owner must have both the desire to act and the ability to act. Property owners are known to have the desire to act but the absence of a suitable system they understand or can have confidence-in and afford, prevents their ability to act.

A newly patented and innovative solution, The Flexible Skirting System, is revealed to offer full property protection against all routes of water ingress. For the first time property owners have a system that is quick and simple to install, aesthetically acceptable and offers less disruption. This system provides protection for all property types (old and new) and is possibly the way forward to enable property owners to make the decision to install flood protection.

In the UK, there are now government grants available for properties at high risk of flooding. For example, Aylesbury Vale District Council has recently been awarded $£ 325,000$ to install flood protection measures on 57 properties, which, depending on property type, equates to $£ 4,500-7,000$ each. Therefore, it is essential that government money be used to provide property owners with protection against all water ingress routes, as failure to ensure this requirement will simply result in repeated flooding. Unfortunately, a major concern is this money will be spent on individual 'kite marked' items, which may not provide property owners with a complete solution and will be a wasted opportunity to assist flood victims and, in doing so, further damage to the reputation of the flood protection industry.

\section{Conclusions}

The Flexible Skirting System (patent GB2452423) offers a cost effective combination of resistance and resilience approaches. Compared to other flood protection measures already commercially available, the system is quick and simple to install, aesthetically acceptable, offers less disruption and is affordable. Moreover, this system is possibly the choice needed to enable property owners to make the decision to install flood protection against all routes of floodwater ingress.

\section{References}

[1] www.unisdr.org

[2] Deming, D. (2005) Global warming, the politicization of science, and Michael Crichton`s state of fear. Journal of Scientific Exploration, 19, $247-$ 256.

[3] Loucks, P., Stedinger, J., Davis, D. \& Stakhiv, E. (2008) Private and Public Responses to Flood Risks. International Journal of Water Resources Development, 24, 541-543.

[4] Stern, N. (2006) Stern Review: The economics of climate change. TSO: London. 
[5] IPCC (2007) Climate Change 2007: The Physical Science Basis. Contribution of Working Group I to the Fourth Assessment Report of the Intergovernmental Panel on Climate Change [Solomon, S., D. Qin, M., Manning, Z., Chen, M., Marquis, K.B., Avery, M., Tignor, H.L. Miller (eds.)]. Cambridge University Press, UK.

[6] Harries, T. (2007) Householder responses to flood risk; the consequences of the search for ontological security. Unpublished PhD Thesis, Middlesex University, UK.

[7] www.aviva.co.uk

[8] Defra (2008) Consultation on policy options for promoting property-level flood protection and resilience. DEFRA: London.

[9] Proverbs, D. \& Lamond, J. (2008) The Barriers to Resilient Reinstatement of Flood Damaged Homes In International Group for Research and Information on Post-Disaster Construction (2008) $4^{\text {th }}$ International i-Rec Conference 2008 Building Resilience: achieving effective post-disaster reconstruction: April 30-May 2, 2008, Christchurch, New Zealand.

[10] McCarthy, S. Tunstall, S. Faulkner, D. \& Penning-Rowsell, E. (2007) Risk perception, community behaviour and social resilience: Update on Flood Risk Management Research Consortium, presentation made at FLOODsite Liaison Seminar, 22 March 2007

[11] Treby, E., Clark, M. \& Priest, S. (2006) Confronting flood risk: Implications for insurance and risk transfer. Journal of Environmental Management, 81, 351-359.

[12] Meijerink, S. \& Dicke, W. (2008) Shifts in the Public-Private divide in flood management. International Journal of Water Resources Development, 24, 499-512.

[13] Werritty, A., Houston, D., Ball, T., Tavendale, A. \& Black, A. (2007) Exploring the Social Impacts of Flood Risk and Flooding in Scotland. School of Social Sciences - Geography, University of Dundee.

[14] Bramley, M. \& Bowker, P. (2002) Improving local flood protection to property, Floods - A New Approach. Proceedings of the Institution of Civil Engineers: Civil Engineering, 150, 49-54.

[15] Broadbent, C. (2004) Improving the Flood Resistance of Domestic Property. Structural Survey, 22, 79-83.

[16] Bowker, P. (2007) Flood resistance and resilience solutions: an R\&D scoping study. R\&D Technical Report. DEFRA: London.

[17] Tapsell, S. \& Tunstall, S. (2008) "I wish I'd never heard of Banbury": the relationship between "place" and the health impacts from flooding. Health and Place, 14, 133-154.

[18] Fundter, D. (2008) Health impacts of large-scale floods: government decision making and resilience of the citizens. Prehospital and Disaster Medicine, 23, 70-73.

[19] Pitt, M. (2007) The Pitt Review. Cabinet Office: London.

[20] Kelman, I \& Spence, R. (2003) A Flood Failure Flow Chart for Buildings. Municipal Engineer, 156, 207-214. 
[21] CIRIA (2002) Reducing the Impact of Flooding-Extemporary Measures, CIRIA Funders Report FR/IP/45. CIRIA: London.

[22] Escarameia, M., Karanxha, A., \& Tagg, D (2007) Quantifying the flood resilience properties of walls in typical UK buildings. Building Services Engineering Research and Technology. 28, 3.

[23] Carroll, B., Morbey, H., Balogh, R. \& Araoz, G. (2008) Flooded homes, broken bonds, the meaning of home, psychological processes and their impact on psychological health in a disaster. Health and Place, 15, 540547.

[24] Fewtrell, L. \& Kay, D. (2008) An attempt to quantify the health impacts of flooding in the UK using an urban case study. Public Health, 22, 446-451.

[25] Proverbs, D. \& Soetanto, R. (2004) Flood Damaged Property-A Guide to Repair. Blackwell: Oxford.

[26] Reacher, M., McKenzie, K., Lane, C., Nichols, T., Kedge. I., Iverson, A., Hepple, P., Walter, T., Laxton, C. \& Simpson, J. (2004) Health impacts of flooding in Lewes: a comparison of reported gastrointestinal and other illness and mental health in flooded and non-flooded households. Journal of Communicable Disease and Public Health, 7, 56-63. 